\title{
Residues of Organic Chlorinated Pesticides in Agricultural Soils of Beijing, China
}

\author{
Y. Shi, ${ }^{1,2}$ F. Meng, ${ }^{3}$ F. Guo, ${ }^{3}$ Y. Lu, ${ }^{1,2}$ T. Wang,,${ }^{1,2}$ H. Zhang ${ }^{1,2}$ \\ ${ }^{1}$ Research Center for Eco-Environmental Sciences, Chinese Academy of Sciences, Beijing 100085, PRC \\ ${ }^{2}$ Graduate School, Chinese Academy of Sciences, Beijing, 100039, PRC \\ ${ }^{3}$ China Agricultural University, Beijing 100094, PRC
}

Received: 23 April 2004/Accepted: 27 October 2004

\begin{abstract}
Concentration of organic chlorinated pesticides (OCPs) were measured in topsoils of a selected farm (NK farm) in Beijing in 1993 and 2003. The results indicated that OCPs, mainly 1,2,3,4,5,6-hexachlorocyclohexane (HCH) and 1,1,1,-trichloro-2,2-bis(p-chlorophenyl) ethane (DDT), degraded greatly in the 20 years after the prohibition of their use. DDT was the major contributors of pollution on the farm with $92.23 \%$ and $81.28 \%$ contributions of total OCP load in soils in 2003 and 1993 respectively. The levels of total DDT and $\mathrm{HCH}$ in the old orchard group, in which cultivation began in 1962, were significantly higher $(p<0.05)$ than those in the new orchard group in which cultivation began in 1991, and all data were higher than the level of barren land $(p<0.05)$. Studying the isomeric and parent substance metabolite ratios indicated there was more application and accumulation of DDT in the old orchard and that DDT in the new orchard had undergone a different degradation time period or perhaps had been applied more recently, but no new input of $\mathrm{HCH}$ was detected. Pollution potential was assessed on the basis of China Soil Environmental Quality Standard.
\end{abstract}

\section{Introduction}

Because of their low cost and high degree of effectiveness, Organic chlorinated pesticides (OCPs) have been used globally since the 1940s. Taking China as an example, until 1983 the use of OCPs, with 1,2,3,4,5,6-hexachlorocyclohexane $(\mathrm{HCH})$ and 1,1,1-trichloro-2,2- bis(p-chlorophenyl) ethane (DDT) as representatives, has made up $50 \%$ of total pesticide use (Hua and Shan 1996). Most OCPs are persistent, bioaccumulated, semivolatile, and highly-toxic, which has led to growing concerns regarding the potential for contamination of the environment and associated effects on human health and wildlife (Hua and Shan 1996; Dou and Zhao 1998; Ma et al. 2001). In the 12 priority persistent organic pollutants listed in

Correspondence to: Yajuan Shi; email: yajuanshi@rcees.ac.cn the 2001 Stockholm Convention on Persistent Organic Pollutants, 9 were OCPs (i.e., aldrin, dieldrin, endrin, DDT, chlordane, heptachlor, mirex, toxaphene, and hexachlorobenzene).

In China, the use and production of aldrin, dieldrin, endrin, toxaphene, chlordane, and heptachlor have been either limited or are nonexistent. The abuse of DDT and $\mathrm{HCH}$ in agricultural application during the 1960s and 1970s was the main contribution to the high levels of their residues detected in the environment and their consequent adverse effects on humans and wildlife (Liu et al. 2001; Wong et al. 2002). In 1983, the use of DDT and $\mathrm{HCH}$ was formally banned in China, yet small amounts of DDT and $\mathrm{HCH}(\gamma-\mathrm{HCH}$, lindane) are still being produced as raw materials for other chemicals or for export.

The remnant levels of OCPs in water, sediments, soils, crops, vegetables, and fruits decreased greatly after the prohibition of these substances. According to a nationwide investigation conducted by the Ministry of Agriculture in 1988 and 1989, the HCH remnant levels in crops decreased by a factor of 10 compared with those in the early 1980s. The same decrease happened with DDT (Lin et al. 2000).

Although the remnant levels of OCPs in China have decreased greatly since the 1980 s, they are still higher than those in developed countries (Zhong et al. 2000; Wong et al. 2002), and their influence has still not disappeared; very low concentrations still exist in the human body and the environment. What is the current status of OCP residues in China? After a survey of OCP residues in food was conducted by the Ministry of Health in 1992 (Zhang and Zhang 2001), there has been no national investigation.

In this article NK farm, in which DDT and $\mathrm{HCH}$ were used in large quantities during 1962 to 1982 , was selected for a case study of OCP remnant levels in agricultural soils. The OCP residues in soils of the old orchard group, in which apple trees started being cultivated in 1962, and the new orchard group, in which cultivation began in 1991, in NK farm were measured in samples taken in 1993 and 2003, 10 years and 20 years, respectively, after their prohibition. By analyzing factors such as cultivation history, history of OCP use, and isomeric and parent substance metabolite ratios, current OCPs status and time trend were determined. Potential risk was assessed using environmental guidelines established in China. 
Table 1. Group, sample description, and selected soil properties

\begin{tabular}{|c|c|c|c|c|}
\hline \multirow[b]{2}{*}{ Group } & \multirow[b]{2}{*}{ Barren land } & \multirow[b]{2}{*}{ New orchard } & \multicolumn{2}{|l|}{ Old orchard } \\
\hline & & & Orchard & New fallow \\
\hline Sample no. & $\mathrm{N} 12$ & $\begin{array}{l}\text { N1, N15, } \\
\text { N16, N17 }\end{array}$ & $\begin{array}{l}\mathrm{N} 2, \mathrm{~N} 3, \mathrm{~N} 4, \mathrm{~N} 6, \mathrm{~N} 7 \\
\mathrm{~N} 8, \mathrm{~N} 9, \mathrm{~N} 10, \mathrm{~N} 13\end{array}$ & N5, N11, N14 \\
\hline Land use & Barren & Orchard & Orchard & $\begin{array}{l}\text { Orchard, but changed } \\
\text { to fallow recently }\end{array}$ \\
\hline $\begin{array}{l}\text { Cultivation } \\
\text { history }\end{array}$ & No cultivation & $\begin{array}{l}\text { Apple trees began } \\
\text { to be cultivated in } 1991\end{array}$ & $\begin{array}{l}\text { Apple trees began to } \\
\text { be cultivated in } 1962\end{array}$ & $\begin{array}{l}\text { Apple trees began to } \\
\text { be cultivated in } 1962 \\
\text { and were fallowed recently: } \\
\text { N5 was fallowed in } 2000, \\
\text { N11 in } 1999 \text {, and N14 in } 1997\end{array}$ \\
\hline Soil texture & Sandy & Sandy loam & Sandy loam & Sandy loam \\
\hline $\begin{array}{l}\text { Organic C (\%) } \\
\quad \text { (in 2003) }\end{array}$ & 1.104 & 1.734 & 1.798 & 1.794 \\
\hline $\begin{array}{l}\text { Organic C (\%) } \\
\quad \text { (in 1993) }\end{array}$ & 0.73 & 1.625 & 2.53 & 2.22 \\
\hline pH (in 2003) & 7.8 & 6.6 & 7.2 & 6.5 \\
\hline pH (in 1993) & 8.1 & 7.5 & 7.6 & 7.4 \\
\hline
\end{tabular}

\section{Materials and Methods}

\section{Study Area and Soil Sampling}

$\mathrm{NK}$ farm is located at E $116.094^{\circ}, \mathrm{N} 40.177^{\circ}$ in a northwestern suburb of Beijing, China. The climate is typically cool monsoon weather with an average annual temperature of $11.6^{\circ} \mathrm{C}$ and an average annual rainfall of $584 \mathrm{~mm}$.

NK farm is dedicated for the cultivation of apple trees. The total orchard area is approximately 140 ha including an area of new orchards cultivated in 1991 that makes up one fourth of the farm. The remaining three fourths of the farm is old orchard in which cultivation began in 1962, with a small part of that field lying fallow since 1997. DDT and $\mathrm{HCH}$ were used at NK farm in large quantities during 1962 to 1982; carbamate, pyrethroids, and organophosphates have been the primary pesticides in use since 1982 . The group, sample description, and selected soil properties are listed in Table 1 .

To investigate the contents of OCPs in the ploughed layer of the 17 orchard sites, grid pattern sampling was carried out in 1993 and 2003. Four subsamples from each of the sampling areas were collected at soil depth $(0$ to $20 \mathrm{~cm})$ with a soil corer. All subsamples were thereafter pooled to obtain one representative sample for each site. Samples were homogenized by sifting through a steel mesh (2-mm grid size). The samples were freeze dried at $-20^{\circ} \mathrm{C}$ and then stored at $4{ }^{\circ} \mathrm{C}$ until analyzed.

\section{Standards, Materials, and Solvents}

The organochlorines were quantified using $p, p^{\prime}$-DDT, $o, p^{\prime}$-DDT, $p, p^{\prime}$ DDE, $p, p^{\prime}$-DDD, $\alpha-\mathrm{HCH}, \beta-\mathrm{HCH}, \gamma-\mathrm{HCH}, \delta-\mathrm{HCH}$, dieldrin, endrin, heptachlor, and chlordane. These standards at $100 \mathrm{mg} / \mathrm{l}$ were supplied by the National Research Center for Certified Reference Materials of China and then diluted to the desired concentration. All solvents obtained from the Beijing Chemical Factory were of analytical grade and were redistilled in an all-glass system before use. Florisil (Beijing Yizhong Chemical Plant) in 100 to 200 mesh was activated for 16 hours at $130^{\circ} \mathrm{C}$; silica gel (Shanghai Changquan Chemical Plant) in 80 to 120 mesh was activated for 4 hours at $110^{\circ} \mathrm{C}$; and anhydrous $\mathrm{Na}_{2} \mathrm{SO}_{4}$ (Beijing Chemical Factory) was dried at $300^{\circ} \mathrm{C}$ for 4 hours. All of the materials were analytical grade, and the activated ones were kept in a desiccator before use.

\section{Sample Preparation and Cleanup}

Samples, $10 \mathrm{~g}$, of freeze-dried soil were mixed with $25 \mathrm{ml}$ hexaneacetone (1:1) and then shaken in an ultrasonic bath for 20 minutes and centrifuged. The extracts obtained were concentrated for subsequent cleanup, transferred to a Florisil column (a glass column $[30 \mathrm{~cm} * 1.5$ i.d.] packed with $9 \mathrm{~g}$ Florisil, $1 \mathrm{~g}$ silica gel, and $2 \mathrm{~g}$ anhydrous $\mathrm{Na}_{2} \mathrm{SO}_{4}$ and pre-eluted with $30 \mathrm{ml}$ hexane) and eluted with a 50-ml eluting mixture ( $15 \%$ acetone and hexane). The eluates were then concentrated and made into a final volume of $1 \mathrm{ml}$ with hexane for gaschromatographic analysis.

\section{Analysis}

The levels of $\mathrm{HCH}$ and DDT were measured using a Hewlettpackard 6890 gas chromatograph equipped with an $\mathrm{Ni}^{63}$ electroncapture detector. An HP Ultra-1 capillary column $(50 \mathrm{~m} * 0.32 \mathrm{~mm}$ i.d. $* 0.17 \mu \mathrm{m}$ film thickness) was used. The carrier gas was helium at a flow rate of $1 \mathrm{ml} / \mathrm{min}$. Nitrogen at a flow rate of $0.6 \mathrm{ml} / \mathrm{min}$ was used as the make-up gas for the electron-capture detector. A 1- $\mu 1$ sample of extract was injected in the splitless mode. The temperature program was as follows: the initial temperature was held at $150^{\circ} \mathrm{C}$ for 2 minutes, then increased at $5^{\circ} \mathrm{C} / \mathrm{min}$ to $200^{\circ} \mathrm{C}$, then maintained for 2 minutes, then increased at $8^{\circ} \mathrm{C} / \mathrm{min}$ to $270^{\circ} \mathrm{C}$ and held for 5 minutes.

A procedural reagent blank was included with each batch of sample, and none of the target compounds were detected in the procedural blanks. OCP residues were quantitatively determined by comparing the area under each peak with the area under the standard peak. The correlation coefficients of OCP calibration curves were all $>0.998$. Matrix spike recovery experiments were also undertaken. The recoveries of $\alpha-, \beta-, \gamma-$, and $\delta-\mathrm{HCH}$ with spiked samples were $92.6 \%, 93.5 \%, 94.7 \%$, and $97.6 \%$, respectively, and those $p, p^{\prime}$-DDT, $o, p^{\prime}$-DDT, $p, p^{\prime}$-DDE, and $p, p^{\prime}$-DDD were $95.8 \%, 99.2 \%, 96.4 \%$, and $95.4 \%$, respectively. The limits of detection of OCPs were described as three of signal-to-noise ratio. The detection limits of $\alpha-, \beta-, \gamma-$ and $\delta-\mathrm{HCH}$ were $0.16,0.059$, $0.099,0.15 \mathrm{ng} / \mathrm{g} \mathrm{d} . \mathrm{w}$, respectively, and those of $p, p^{\prime}$-DDT, $o, p^{\prime}$ DDT, $p, p^{\prime}$-DDE, and $p, p^{\prime}$-DDD were $0.37,0.056,0.094$, and 0.096 ng/g d.w., respectively. The relative standard deviation varied from $2.2 \%$ to $6.0 \%$. 
Table 2. Descriptive statistics of total HCH and DDT in NK farm soils

\begin{tabular}{|c|c|c|c|c|}
\hline \multirow[b]{2}{*}{ Statistics } & \multicolumn{2}{|l|}{$\sum \mathrm{HCH}$} & \multicolumn{2}{|l|}{$\sum \mathrm{DDT}$} \\
\hline & In 2003 & In 1993 & In 2003 & In 1993 \\
\hline No. of samples & 17 & 17 & 17 & 17 \\
\hline Geometric mean (mg/kg d.w,) & 0.0320 & 0.3270 & 0.3813 & 1.4197 \\
\hline $95 \%$ confidence interval & $0.0127-0.0805$ & $0.1123-0.8783$ & $0.1514-0.9594$ & $0.5737-3.5135$ \\
\hline Geometric SD & 6.0183 & 7.9930 & 6.0302 & 5.8262 \\
\hline Minimum(mg/kg d.w.) & 0.0020 & 0.012 & 0.0072 & 0.044 \\
\hline Maximum(mg/kg d.w.) & 0.7603 & 9.486 & 2.9100 & 24.615 \\
\hline
\end{tabular}

DDT $=1,1,1$-trichloro-2,2-bis (p-chlorophenyl) ethane.

$\mathrm{HCH}=1,2,3,4,5,6$-hexachlorocyclohexane.

\section{Statistics}

OCP data and their logarithmic transformations were subjected to Shapiro-Wilk test to define their distribution. Because of the normal distribution of the logarithmic transformation data, the values presented are geometric means together with their 95\% confidence intervals (lower and upper bound). Homogeneity of variance was tested using Levene's test. A paired-sample Student $t$-test was used to examine the difference between OCP levels in 1993 and 2003. Analysis of variance (ANOVA) was used to compare the difference among the barren land, the old orchard group, and the new orchard group. After ANOVA, analysis was conducted, Student independent samples $t$ test was used to compare the difference between old and new orchard groups and between the orchard and the new fallow subgroups. All statistical analysis was conducted using SPSS software.

\section{Results and Discussion}

\section{OCP Levels in the Studied Area}

Many of the chlorinated pesticides commonly detected in other regions of the world-such as dieldrin, endrin, toxaphene, and heptachlor-were undetectable in our samples. The major chlorinated pesticides detected in these samples were $\mathrm{HCH}$ and DDT families. Table 2 lists the descriptive statistics of total $\mathrm{HCH}$ and DDT levels in NK farm soils detected in 1993 and 2003. Total soil HCH content in 2003 ranged from 0.0020 to $0.7603 \mathrm{mg} / \mathrm{kg}$ d.w. with a geometric mean of $0.0320 \mathrm{mg} / \mathrm{kg}$ d.w. and a low range of $95 \%$ confidence interval in the geometric mean $(0.0127$ to 0.0805$)$. Total soil DDT content in 2003 ranged between 0.0072 and $2.9100 \mathrm{mg} / \mathrm{kg}$ d.w. with a geometric mean of $0.3813 \mathrm{mg} / \mathrm{kg} \mathrm{d.w}$. and a larger range of $95 \%$ confidence interval for geometric mean $(0.1514$ to 0.9594). Total $\mathrm{HCH}$ and DDT presented at higher levels in 1993.

DDT was a major concern of OCP pollution on the farm with $92.23 \%$ and $81.28 \%$ contribution to total pesticide concentration in 2003 and 1993, respectively. DDT is resistant to biodegradation and is absorbed strongly by soil particles (Keith 1997). The relatively high levels of DDT indicated that it was highly persistent in the top layers of the study area.

Current and historic $\mathrm{HCH}$ and DDT levels in NK farm soils were generally comparable with literature data from other foreign and domestic orchards in the corresponding survey year (Table 3). For example, HCH and DDT residues in NK farm surface soils in 2003 were on the same order with con- centrations reported from orchard soils of Zhejiang Province in China, and DDT levels were lower than those in orchard soils of New Zealand in 2002. NK farm also showed contaminant levels of DDT in 1993 similar to those in Canadian orchard soils in 1994.

Orchard fields are dynamic systems of particular environmental concern because they exhibit a high capacity to concentrate and deliver pollutants. This study proved that orchard soils have much higher levels of $\mathrm{HCH}$ and DDT, than reported in from other agricultural soils (Table 3). Compared with rice fields in Jiaxing City, NK farm in 2003 had rather large deviations of $\mathrm{HCH}$ and DDT remnant levels and much higher maximum $\mathrm{HCH}$ and DDT levels. Current $\mathrm{HCH}$ and DDT residue levels were even 1 to 2 orders of magnitude higher than those in agricultural soils of the Taihu region of China and cotton fields in Geogia, which were surveyed recently. NK farm in 1993 showed contaminant levels of DDT and $\mathrm{HCH}$ some 10-fold higher than those in cotton and rice fields in Jiangsu in 1992 and 1 to 2 orders higher than those detected in German agricultural soils during 1995 and 1996.

\section{Comparison Between Present and Historic OCP Data}

Statistics showed there was a significant difference between total HCH level in 1993 and the level in 2003 (paired-samples Student $t$ test, $t=-6.175, p<0.05$ ). For each of the soil samples, the total $\mathrm{HCH}$ concentration had decreased greatly in 2003 compare with 1993 (Fig. 1a). The geometric mean level in $\mathrm{mg} / \mathrm{kg}$ of total $\mathrm{HCH}$ dry weight $(0.0320)$ in 2003 was considerably lower than that in 1993 (0.3270).

The 2003 results showed that most soils, with the exception of N11, had lower contents compared with 1993 data (Fig. 1b). Total DDT concentration in 2003 was significantly lower than that in 1993 (paired-samples Student $t$ test, $t=-4.917, p<$ 0.05). The geometric mean level of DDT $(0.3813 \mathrm{mg} / \mathrm{kg} . \mathrm{d} . \mathrm{w})$ in 2003 was considerably lower than that in $1993(1.4197 \mathrm{mg} /$ kg.d.w).

As in the whole of China, the use of $\mathrm{HCH}$ and DDT has been banned at NK farm since 1982. Therefore, the farm has been undergoing degradation, and there should have been no new input during the next 2 decades. This may explain the overall decrease in all of the selected OCPs detected in 1993 and 2003.

Comparisons between the 1993 and 2003 data revealed a higher decrease in $\mathrm{HCH}(90.21 \%)$ than DDT $(73.14 \%)$ during 
Table 3. Comparison of OCP levels (mg/kg d.w.) in surface soils from other geographic areas (domestic and abroad)

\begin{tabular}{|c|c|c|c|c|c|c|c|}
\hline \multirow[b]{2}{*}{ Area } & \multirow[b]{2}{*}{ Year } & \multirow[b]{2}{*}{ Land use } & \multicolumn{2}{|l|}{$\mathrm{HCH}$} & \multicolumn{2}{|l|}{ DDT } & \multirow[b]{2}{*}{ References } \\
\hline & & & Range & Mean & Range & Mean & \\
\hline Beijing, China & 2003 & Orchard & $0.0020-0.7603$ & 0.032 & $0.00721-2.9100$ & 0.3813 & This work \\
\hline Zhejiang, China & 1999 & Orchard & $0.0011-0.0763$ & 0.015 & $0.0015-5.6425$ & 0.7282 & Zhao and Ma 2001 \\
\hline Auckland, New Zealand & 2003 & Orchard & & & $<0.03-24.41$ & $\begin{array}{l}\text { Median } \\
1.17\end{array}$ & Gaw et al. 2003 \\
\hline Jiaxing, China & 2001 & Rice field & $0.0186-0.0554$ & 0.0347 & $0.0286-0.0718$ & 0.0489 & Zhao et al. 2002 \\
\hline Taihu, China & 2001 & Agricultural & $0-0.0034$ & & $0-0.0053$ & & Feng et al. 2003 \\
\hline Georgia, USA & 1999 & Cotton field & $<0.0001-0.00049$ & & $0.00034-0.034$ & 0.013 & Kannan 2003 \\
\hline Beijing, China & 1993 & Orchard & $0.012-9.486$ & 0.327 & $0.044-24.615$ & 1.419 & This work \\
\hline Simcoe, Canada & 1994 & Orchard & & & & 7.1 & Harris et al. 2000 \\
\hline Jiangsu, China & 1992 & Cotton field & & 0.032 & & 1.230 & Lin et al. 2000 \\
\hline Jiangsu, China & 1992 & Rice field & & 0.045 & & 0.053 & Lin et al. 2000 \\
\hline Germany & 1995 to 1996 & Agricultural & $0.0046-0.0115$ & & $0.0279-0.173$ & & Manz et al. 2001 \\
\hline
\end{tabular}

DDT $=1,1,1$-trichloro-2,2-bis (p-chlorophenyl) ethane.

$\mathrm{HCH}=1,2,3,4,5,6$-hexachlorocyclohexane.

$\mathrm{OCP}=$ Organic chlorinated pesticide .

the 10 years. This may be related to the differences in their chemical structures, which was illustrated by specific parameters.

$\mathrm{HCH}$ has much higher water solubility, higher vapor pressure, lower octanol-water coefficient, and lower Henry's Law constant than DDT (e.g., the water solubility of $\mathrm{HCH}$ isomers ranges between 0.24 and $31.4 \mathrm{mg} / \mathrm{l}$, two or three orders of magnitude higher than that of the DDT family, which ranges between 0.0055 and $0.1 \mathrm{mg} / 1$ [Mackay D et al. 1997]). In this regard, $\mathrm{HCH}$ presents an easier ability to degrade and transfer from soil to liquid and atmosphere and thus less persistent in the environment than DDT.

\section{Comparison Between OCP Levels in the Old Orchard and New Orchard Groups}

Statistics showed there is significant difference among OCPs in the soils of the old orchard group, the new orchard group and the barren land (ANOVA $F=4.928, p<0.05$ for $\sum \mathrm{HCH}$ in 2003; $F=20.257, p<0.05$ for $\sum \mathrm{HCH}$ in 1993; $F=21.522, p<0.05$ for $\sum$ DDT in 2003; and $F=14.012, p<$ 0.05 for $\sum$ DDT in 1993). The OCP levels in barren land (N12) were lower than all other data, and the levels of total DDT and $\mathrm{HCH}$ in the old orchard group were significantly higher than those in the new orchard group (Table 4).

DDT and $\mathrm{HCH}$ were extensively used in the old orchard group during the period 1962 to 1982, whereas few OCPs were applied in the new orchard group since it began cultivation in 1991, 9 years after the prohibition of the two pesticides; therefore, there was significant difference in OCP application between the two orchard groups. The intensity of OCP degradation depends on several environmental factors such as soil type, $\mathrm{pH}$, redox potential, organic carbon content, and microbial biomass (Hitch and Day 1992) as well as anthropogenic activities (e.g., land use, fertilization, and pesticide application). Because all other factors remain similar between the two groups, the different OCP residue levels may related to the differences in their application.
In the old orchard group, no significant difference between the orchard subgroup and the new fallow subgroup (Table 5) was noted (independent-samples Student $t$ test, $t=1.817, p>$ 0.05 for $\sum \mathrm{HCH}$ in 2003; $t=1.363, p>0.05$ for $\sum \mathrm{HCH}$ in 1993 ; $t=1.150, \mathrm{p}>0.05$ for $\sum$ DDT in 2003; and $t=1.824$, $p>0.05$ for $\sum$ DDT in 1993). This is reasonable because there should have been no new input of DDT and HCH Since 1997, the 15th year after prohibition and when the soils started to become fallow (see Table 1 for the cultivation history of the soils). In theory, the two subgroups were exposed to the same OCP load and degradation period.

\section{Previous and Current OCP Input}

Studying the isomeric and parent substance metabolite ratios enables past and present pollutant emission sources to be distinguished. The absolute measurement of individual isomers within the DDT and HCH in 2003 (Fig. 2) showed differences in the concentrations between the groups.

Technical $\mathrm{HCH}$ is the mixture of $55 \%$ to $80 \% \alpha-\mathrm{HCH}, 5 \%$ to $14 \% \beta-\mathrm{HCH}, 12 \%$ to $14 \% \gamma-\mathrm{HCH}$ (lindane), $2 \%$ to $10 \%$ $\delta-\mathrm{HCH}$, and $3 \%$ to $5 \% \epsilon-\mathrm{HCH}$. Lindane has the most potent insecticidal properties. Lindane can be completely decomposed or biotransformed into other $\mathrm{HCH}$ isomers in agricultural soils (Liu et al. 2001) and in upper soils has an average half-life of approximately 2 months (Turnbull 1997), although its exact half-life depends closely on the soil type. If the $\gamma-\mathrm{HCH}$ isomer predominates in relative terms, new inputs must be present in the soil. In all the soil samples from NK farm, the highest concentration of $\mathrm{HCH}$ isomers was measured for $\beta-\mathrm{HCH}$ (Fig. 2a), indicating no new input of $\mathrm{HCH}$ on the farm.

The ratio of $\alpha-\mathrm{HCH}$ to $\gamma-\mathrm{HCH}$ ranged from 1.000 to 2.636 with a mean of 1.753 in the old orchard group and from 0.520 to 1.000 with a mean of 0.807 in the new orchard, group. The ratio of $\alpha-\mathrm{HCH}$ to $\beta-\mathrm{HCH}$ ranged between 0.003 and 0.223 with a mean of 0.040 in the old orchard group and from 0.034 to 0.177 with a mean of 0.093 in the new orchard group. Compared with the new orchard group, the higher ratio of $\alpha-\mathrm{HCH}$ to $\gamma-\mathrm{HCH}$ and lower ratio of $\alpha-\mathrm{HCH}$ to $\beta-\mathrm{HCH}$ in the old orchard group indicated the higher percentage of $\beta-\mathrm{HCH}$ 


\section{a) $\mathrm{HCHs}$}

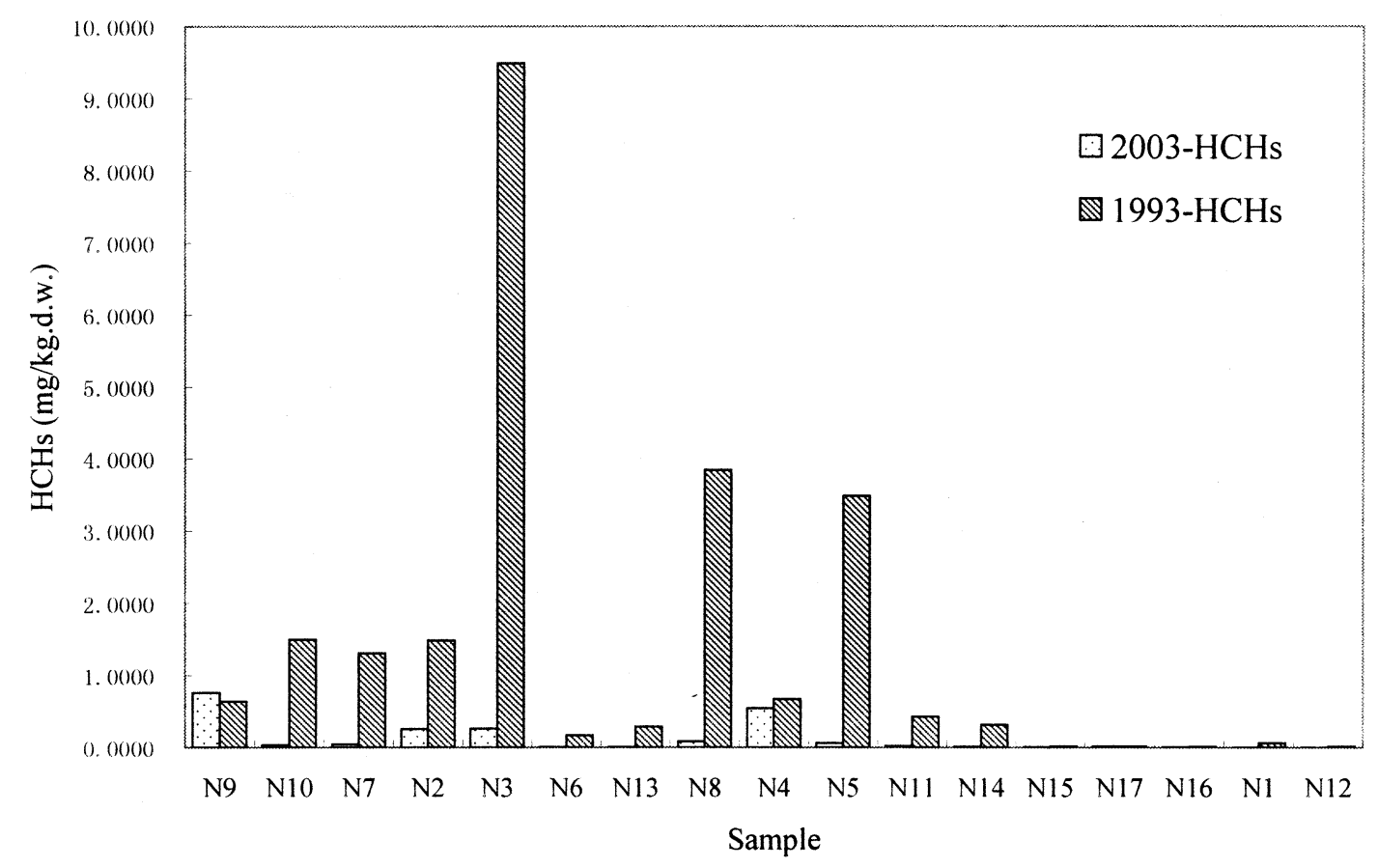

b) DDTs

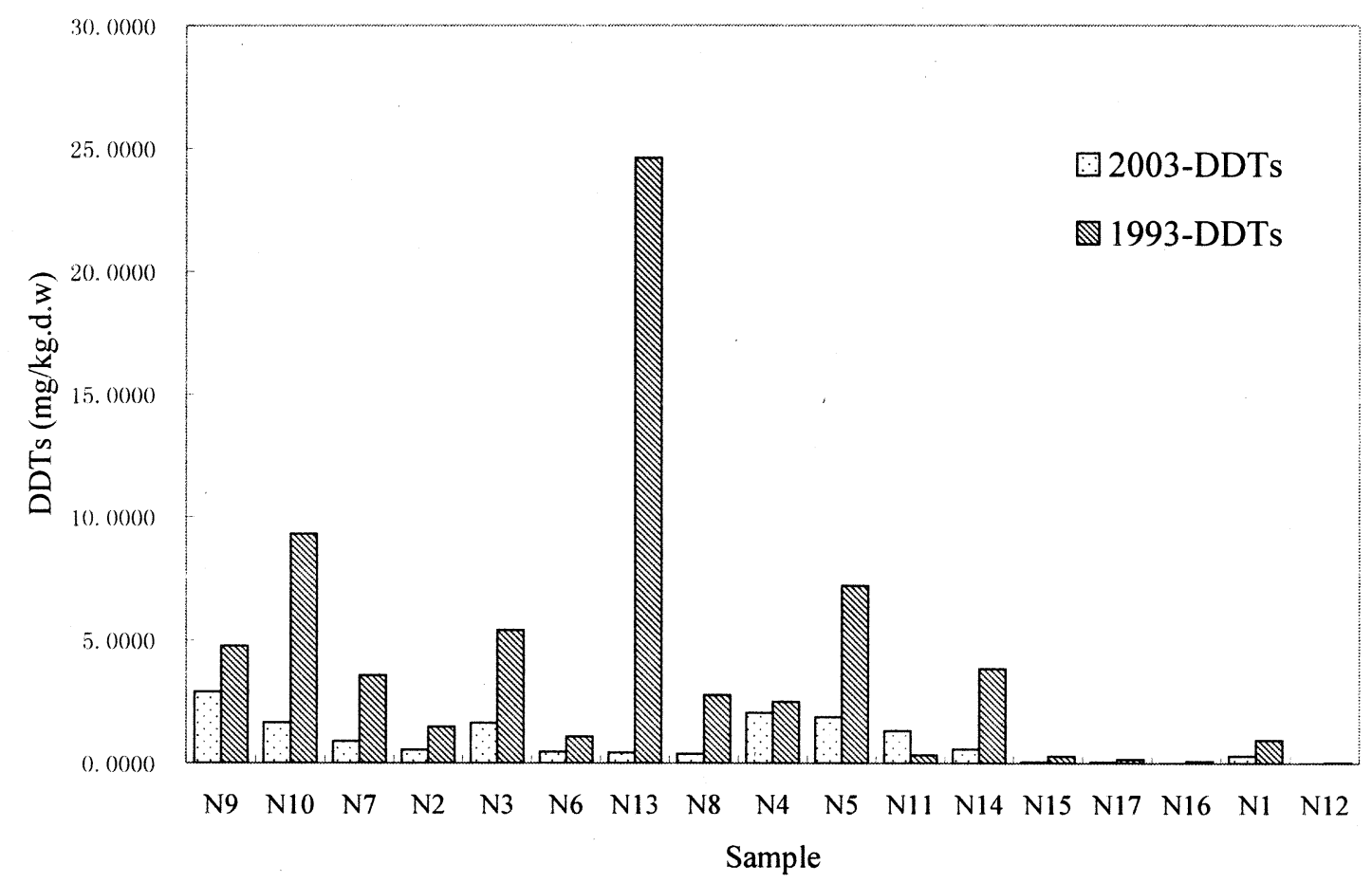

Fig. 1. Concentration of total (a) HCH and (b) DDT in 2003 and 1993. DDT = 1,1,1-trichloro-2,2-bis(p-chlorophenyl) ethane; HCH = 1, 2, 3, 4, 5, 6-hexachlorocyclohexane.

and can be explained by the isomerization of $\alpha$ - to $\beta-\mathrm{HCH}$ and of $\gamma$ - via $\alpha$ - to the more stable $\beta-\mathrm{HCH}$, which is energetically more favorable (Wu et al. 1997) and thus the higher $\mathrm{HCH}$ residue level in soils.
In the DDT group, the highest levels recorded were between approximately 0.0012 and $1.4480 \mathrm{mg} / \mathrm{kg} \mathrm{d}$.w. for $p, p^{\prime}$-DDE; between 0.0009 and $0.245 \mathrm{mg} / \mathrm{kg}$ d.w. for $p, p^{\prime}$-DDD; between 0.0013 and $0.4030 \mathrm{mglkg}$ d.w. for $o, p$ '-DDT, and between 
Table 4. Comparison between concentrations of OCP levels in the old orchard and new orchard groups (mg/kg d.w.)

\begin{tabular}{|c|c|c|c|c|c|c|c|c|}
\hline \multirow[b]{2}{*}{$\begin{array}{l}\text { Survey } \\
\text { year }\end{array}$} & \multirow[b]{2}{*}{ Pollutants } & \multirow[b]{2}{*}{ Barren land } & \multicolumn{3}{|l|}{ Old orchard } & \multicolumn{3}{|c|}{ New orchard } \\
\hline & & & $\begin{array}{l}\text { Geometric } \\
\text { mean }\end{array}$ & $\begin{array}{l}95 \% \text { Confidence } \\
\text { interval }\end{array}$ & Geometric SD & $\begin{array}{l}\text { Geometric } \\
\text { mean }\end{array}$ & $\begin{array}{l}\text { 95\% Confidence } \\
\text { interval }\end{array}$ & $\begin{array}{l}\text { Geometric } \\
\text { SD }\end{array}$ \\
\hline 2003 & $\sum \mathrm{HCH}$ & 0.002 & 0.0642 & $0.0234-0.1764$ & 4.9084 & 0.0079 & $0.0019-0.0329$ & 0.8955 \\
\hline 1993 & $\sum \mathrm{HCH}$ & 0.020 & 1.006 & $0.4689-2.1590$ & 3.3259 & 0.0226 & $0.0068-0.0746$ & 0.7512 \\
\hline 2003 & $\sum \mathrm{DDT}$ & 0.013 & 0.9936 & $0.6338-1.5576$ & 2.0291 & 0.0509 & $0.0043-0.5932$ & 1.5459 \\
\hline 1993 & $\sum \mathrm{DDT}$ & 0.044 & 3.381 & $1.6777-6.8135$ & 3.0128 & 0.2505 & $0.0487-1.2881$ & 1.0290 \\
\hline
\end{tabular}

DDT $=1,1,1$-trichloro-2,2-bis(p-chlorophenyl) ethane.

$\mathrm{HCH}=1,2,3,4,5,6$-hexachlorocyclohexane.

OCP $=$ Organic chlorinated pesticide.

Table 5. Comparison between OCP concentrations in the orchard and new fallow subgroups (mg/kg d.w.)

\begin{tabular}{|c|c|c|c|c|c|}
\hline \multirow[b]{2}{*}{ Survey year } & \multirow[b]{2}{*}{ Pollutants } & \multicolumn{2}{|l|}{ Orchard } & \multicolumn{2}{|l|}{ New fallow } \\
\hline & & $\begin{array}{l}\text { Geometric } \\
\text { mean }\end{array}$ & $\begin{array}{l}\text { 95\% Confidence } \\
\text { interval }\end{array}$ & $\begin{array}{l}\text { Geometric } \\
\text { mean }\end{array}$ & $\begin{array}{l}95 \% \text { Confidence } \\
\text { interval }\end{array}$ \\
\hline 2003 & $\sum \mathrm{HCH}$ & 0.0856 & $0.0229-0.3187$ & 0.0271 & $0.0032-0.2277$ \\
\hline 1993 & $\sum \mathrm{HCH}$ & 1.0942 & $0.4228-2.8319$ & 0.7822 & $0.0308-19.842$ \\
\hline 2003 & $\sum \mathrm{DDT}$ & 0.9498 & $0.5261-1.7147$ & 1.1373 & $0.2588-4.9977$ \\
\hline 1993 & $\sum \mathrm{DDT}$ & 3.9689 & $1.9209-8.2009$ & 2.0900 & $0.0363-12.0267$ \\
\hline
\end{tabular}

DDT $=$ 1,1,1 -trichloro-2,2-bis(p-chlorophenyl) ethane.

$\mathrm{HCH}=1,2,3,4,5,6$-hexachlorocyclohexane.

$\mathrm{OCP}=$ Organic chlorinated Pesticide.

Table 6. Probability that the sampling group exceeded the guide value of the specific grade according to the China Soil Environmental Standard (GB15618-95)

\begin{tabular}{lllll}
\hline Year & Pollutants & Old orchard & New orchard & Total farm \\
\hline 2003 & $\sum$ HCH & I $>50 \%$, II $<16 \%$, III $<2.5 \%$ & I $<2.5 \%$ & I $<50 \%$, II $<16 \%$ \\
1993 & $\sum$ HCH & I $>97.5 \%$ & I $<2.5 \%$ & I $>50 \%$, II $<50 \%$, III $<50 \%$ \\
2003 & $\sum$ DDT & I $>97.5 \%$, II $>50 \%$, III $>50 \%$ & I $>50 \%$, II $<2.5 \%$ & I $>84 \%$, II $<50 \%$, III $<50 \%$ \\
1993 & $\sum$ DDT & III $>84 \%$ & I $>97.5 \%$, II $<2.5 \%$ & I $>84 \%$, II $>50 \%$, III $>50 \%$ \\
\hline
\end{tabular}

Grade I: HCHs $\leq 0.05 \mathrm{mg} / \mathrm{kg}$ d.w. and DDT $=0.05 \mathrm{mg} / \mathrm{kg}$ d.w.; grade II: HCHs $\leq 0.5 \mathrm{mg} / \mathrm{kg}$ d.w. and DDT $=0.5 \mathrm{mg} / \mathrm{kg} \mathrm{d} . \mathrm{w}$.; Grade 111 : $\mathrm{HCH} \leq 1.0 \mathrm{mg} / \mathrm{kg}$ d.w. and DDT $=1.0 \mathrm{mg} / \mathrm{kg}$ d.w.

DDT $=1,1,1$-trichloro-2,2-bis(p-chlorophenyl) ethane.

$\mathrm{HCH}=1,2,3,4,5,6$-hexachlorocyclohexane.

0.0024 and $0.814 \mathrm{mg} / \mathrm{kg} \mathrm{d} . \mathrm{w}$. for $p, p^{\prime}$-DDT. DDE was the dominant isomer in the soils (Fig. 2b).

The ratio of $p, p^{\prime}$-DDE to $p, p^{\prime}$-DDT which is an indication of the historic accumulation of $p, p^{\prime}$-DDT, was approximately 1.927 in the old orchard. This was higher than the $1.266 \mathrm{ob}-$ tained in the new orchard, thus indicating the greater accumulation of DDT in the old orchard group.

The DDT-to-(DDD+DDE) ratio can be used to evaluate the degree of DDT degradation (Tavares et al. 1999). The high value of this ratio indicates slow degradation of DDT or addition of unaltered DDT contamination to the samples. The higher ratio of DDT to (DDD+DDE) (mean of 0.890 ) in the new orchard soils than the old orchard soils (mean of 0.751 ) indicated that DDT had undergone a different degradation period or suggested a more recent application of $p, p^{\prime}$-DDT in the new orchard. The large amount of DDT residue disposed of in the past might be an explanation. It also may be related to the production and use of dicofol around China, in which $3.54 \%$ to $10.8 \%$ of DDT exists as major impurity (Yu et al.
2001). Until now, the continuing input of DDT caused by dicofol should be an important aspect for the analysis of DDT residues and elimination strategy in China.

\section{Pollutant Potential Evaluation of the Soil Findings}

An OCP pollutant potential was assessed on the basis of the China Soil Environmental Standard. The assessment was made by estimating the Probability to Exceed the Guide value. The probability is estimated by the distribution of the ratio of the estimation of the sampling group to the guide value (Shen 1995). The ratio is computed as such:

$$
R=\frac{M g \times S g^{(\mathrm{k})}}{G}
$$

where, $\mathrm{R}$ is the ratio of the estimation of the sampling group to the guide value; $M_{g}$ is the geometric mean; $S_{g}$ is 
a) $\mathrm{HCHs}$

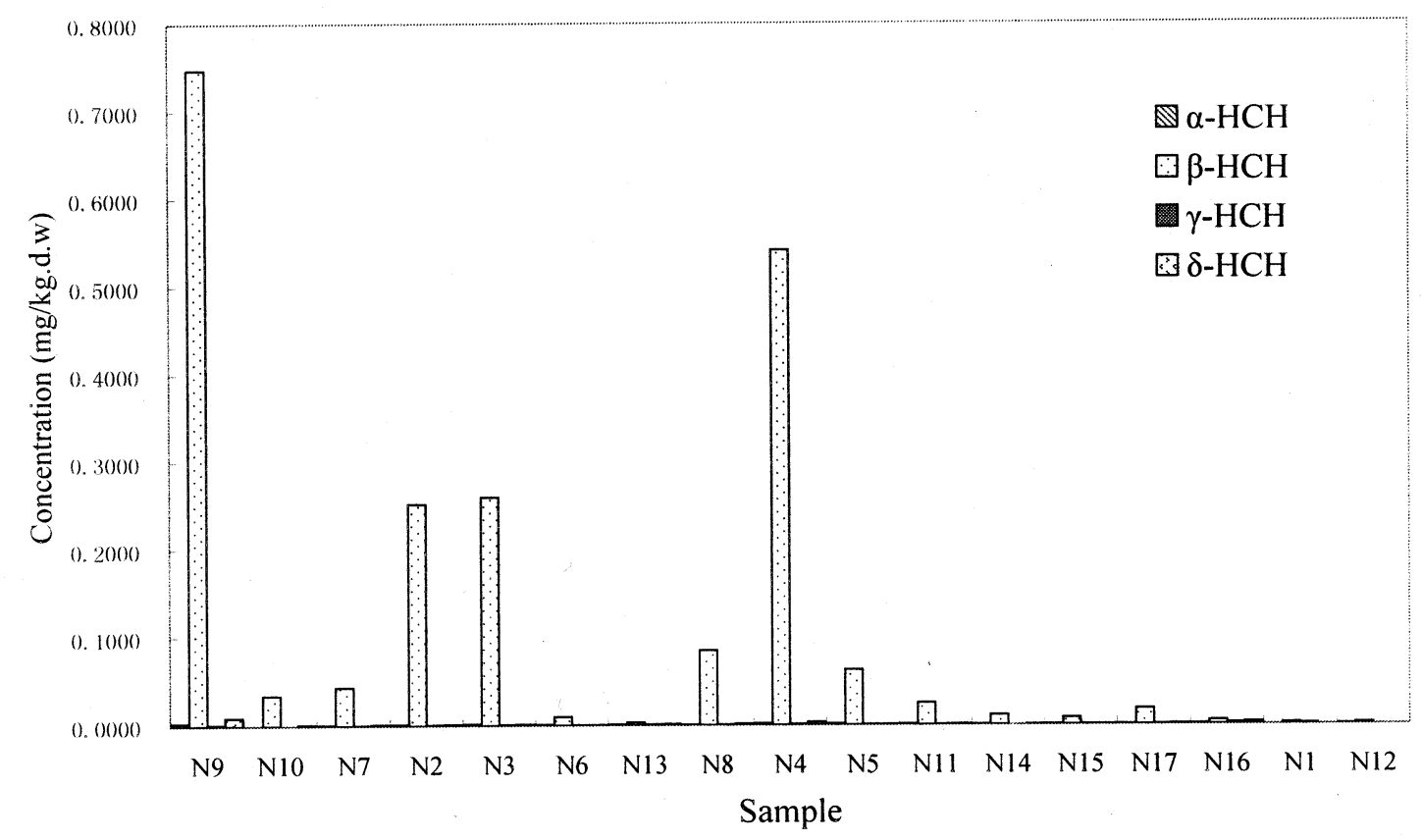

b)DDTs

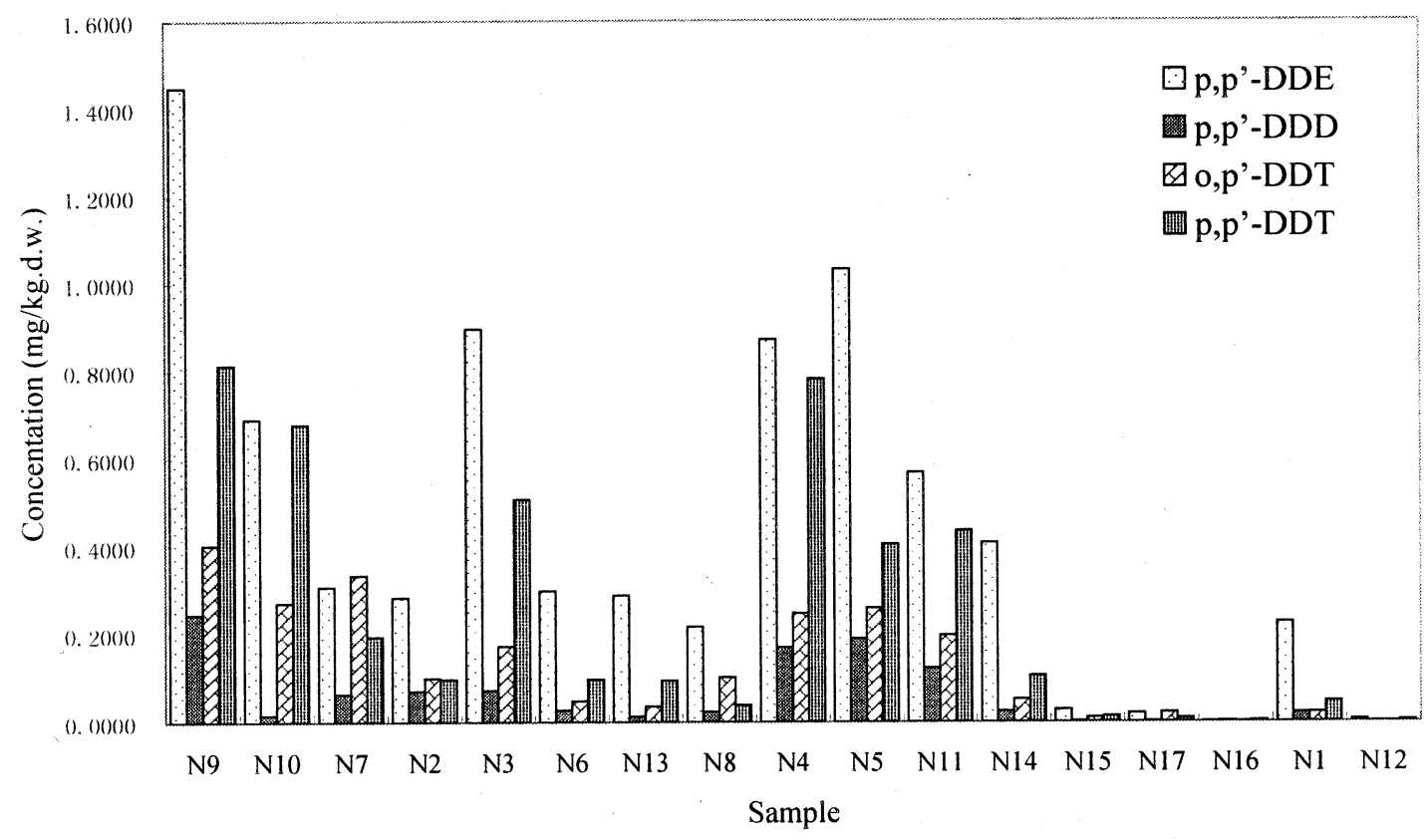

Fig. 2. Concentration of OCP isomers in 2003. OCP $=$ organic chlorinated pesticides.

the geometric $\mathrm{SD}$; $\mathrm{K}$ is an integer $(-2 \leq \mathrm{K} \leq 2)$; and $\mathrm{G}$ is the guide value to be compared.

The probability that the sampling group exceeded the guide value of the specific grade of China Soil Environmental Standard (Table 6). If the pollution level was less than grade I (background value), it was defined as no pollution; if the pollution level was between grade I and grade II, it was defined as low pollution; if the pollution level was between grade
II and III, it was defined as moderate pollution; and if the pollution level exceeded grade III, it was defined as high pollution.

For the new orchard group, $\mathrm{HCH}$ pollution in soils from the 1993 and 2003 samples was categorized as no pollution; in 1993, DDT pollution exceeded grade I but was less than grade II and was categorized as low pollution; in 2003, the pollution was lower than in the 10 years before but still in low-pollution 
range. At present, the new orchard can be regarded as having slight $\mathrm{HCH}$ pollution and low DDT Pollution.

In the old orchard group, the $\mathrm{HCH}$ and DDT pollution in soils in 2003 was decreased from that in 1993. The $\mathrm{HCH}$ pollution levels in both of the sampling years are at a moderate level, whereas the DDT pollution level decreased from a high pollution level in 1993 to a moderate pollution level in 2003. The total farm can be regarded as having had low $\mathrm{HCH}$ pollution in both 1993 and 2003 and as having had high DDT pollution in 1993 but a low DDT level in 2003.

Acknowledgments. The authors thank Elizabeth Douglas and James Douglas for reviewing the manuscript and providing helpful suggestions. We also thank Guibin Jiang, Ruiqiang Yang, and Jiyan Liu for technical support during the measurement of OCPs in soils. This study was supported by Chinese Academy of Sciences (Grant No. KZCX2414).

\section{References}

Dou W, Zhao ZX (1998) Contamination of DDT and BHC in water, sediments and fish muscle from Baiyangdain Lake. Acta Sci Circums 18:308-312

Feng K, Yu BY, Ge DM, Wong MH, Wang XC, Cao ZH (2003) Organo-chlorine pesticide (DDT and $\mathrm{HCH}$ ) residues in the Taihu Lake Region and its movement in soil-water system I. Field survey of DDT and $\mathrm{HCH}$ residues in ecosystem of the region. Chemosphere 50:683-687

Gaw SK, Palmera G, Kimb ND, Wilkinsa AL (2003) Preliminary evidence that copper inhibits the degradation of DDT to DDE in pip and stonefruit orchard soils in the Auckland region, New Zealand. Enviro Pollu 122:1-5

Harris ML, Wilson LK, Elliott JE, Bishop CA, Tomlin AD, Henning KV (2000) Transfer of DDT and metabolites from fruit orchard soils to American robins (Turdus migratorius) twenty years after agricultural use of DDT in Canada. Arch Environ Contam Toxicol 39:205-220

Hitch RK, Day HR (1992) Unusual persistence of DDT in some western USA soils. Bull Environ Contam Toxicol 48:259-264

Hua XM, Shan ZJ (1996) The production and application of pesticides and factor analysis of their pollution in environment in China. Adv Environ Sci 4:33-35

Kannan K, Battula B, Loganathan BG, Hong CS, Lam WH, Villeneuve DL, Sajwan K, Giesy JP (2003) Trace organic con- taminants, including toxaphene and trifluralin, in cotton field soils from Georgia and South Carolina, USA. Arch. Environ. Contam. Toxicol. 45:30-36

Keith LH (1997) Environmental endocrine disruptors. A handbook of property data. Wiley, NewYork, NY, p 621

Lin YS, Gong RZ, Zhu ZL (2000) Pesticide and eco-environment protection. Chemical Industry Press, Beijing, PRC, pp 14-15

Liu XM, Peng P, Huang WL, Sheng GY, Fu JM (2001) Environmental behavior and research progress of HCHs. Agric Environ Dev 2:38-40

Ma M, Wang ZJ, Sodergren AJ (2001) Contamination of PCBs and organochlorinated pesticides in the sediment samples of guanting reservoir and Yongding River. Environ Chem 20:238-243

Mackay D, Shiu WY, Ma KC (1997) Illustrated handbook physical chemical properties of environmental fate of organic chemicals Volume V. Lewis, Boca Raton, FL

Manz M, Wenzel KD, Dietze U, Schuurmann G (2001) Persistent organic pollutants in agricultural soils of central Germany. Sci Total Enviro 277:187-198

Shen SZ (1995) Methods of mathematical statistics for analysis of environmental quality. City Environ Eco 8:42-46

Tavares TM, Beretta M, Costa MC (1999) Ratio of DDT/DDE in the all Saints Bay, Brazil and its use in environmental management. Chemosphere 38:1445-1452

Turnbull A (1997) Chlorinated pesticides. In: Hester RE, Harrison RM (ed) Chlorinated organic micropollutants. Issue in Environmental Science and Technology Series. The Royal Society of Chemistry, Letchworth, UK, pp 113-135

Wong CKC, Leung KM, Poon BHT, Lan CY, Wong MH (2002) Organochlorine hydorcarbons in human breast milk collected in Hong Kong and Guangzhou. Arch Environ Contam Toxicol 43:364-372

Wu WZ, Xu Y, Schramm KW, Kettrup A (1997) Study of sorption, biodegredation and isomerization of $\mathrm{HCH}$ in simulated sediment/ water system. Chemosphere 35:1887-1894

Yu HF, Zhan XD, Zhang XM, Zhu ZQ, Liu JL (2001) Dynamic study on the accumulative levels of organic pesticides in the mother's milk in Beijing. J Environ Health 18:352-354

Zhang DD, Zhang XH (2001) Pesticide pollution and control. Chemical Industry Press, Beijing, PRC, p 31

Zhao L, Ma YJ (2001) Analysis of the status of organochlorinated pesticides in the agricultural environment. Agric Environ Dev 1:37-39

Zhao YW, Chen K, Ma XY, Yao KY (2002) A study on the residue of the organochloride pesticide in soil and rice. Zhejiang Prey Med $14: 1-3$

Zhong WK, Hao J, Sun MX, Chen YL (2000) Pesticides residues in food in China. Pesticide 39:1-4 